\title{
Using Online Game for Indonesian EFL Learners to Enrich Vocabulary
}

https://doi.org/10.3991/ijim.v15i01.17513

\author{
Like Raskova Octaberlina ( $₫)$, Imam Rofiki \\ Universitas Islam Negeri Maulana Malik Ibrahim, Malang, Indonesia \\ likeraskova2004@gmail.com
}

\begin{abstract}
For students of English as a Foreign Language (EFL), vocabulary mastery is an essential component of language skills. Vocabulary may contribute to the success of language skills. However, most students had some trouble learning vocabulary. Vocabulary learning requires an advanced technology such as online game. Therefore, this paper aims to investigate the outcome of using an online game named SpellingCity to enrich vocabulary, which is a part of modern gamification. The research design is to have 22 students finish one turn game of SpellingCity and then fill out a survey and interview at the end of the data collection process. The result was that all students agree that using SpellingCity increase their vocabulary acquisition besides of also learning the pronunciation. SpellingCity simple interface design is also found to be one of the factors why SpellingCity considered interesting and easy to play by these students.
\end{abstract}

Keywords-EFL, online game, language learning, SpellingCity , vocabulary

\section{$1 \quad$ Introduction}

The teaching of vocabulary is one of the most talked parts of teaching English as a Foreign Language (EFL) [1]-[5]. It is not anything but difficult to do because individuals mostly feel burnt out on boundless number of vocabulary. To a few, vocabulary instructing even shows up as an exercise in futility. Though, as recently contended, vocabulary authority is the pathway to acing four vital aptitudes in English. Along these lines, both educators and students ought to understand this and put aside ruinous musings that demotivate ability to learn however much vocabulary as could reasonably be expected. Besides, the English educators would be wise to show English vocabulary first than different parts of this language, for example, sentence structure, talking, tuning in, perusing and composing. On the off chance that students ace a lot of vocabulary, it will be simple for them to learn different parts of English language. Recent researches demonstrates that teaching vocabulary might be difficult in light of the fact that plenty of educators are unsure about the best practice in vocabulary teaching and do not realize where to start to frame an instructional accentuation on word learning [6]-[8]. One of the most problematic problems of teaching vocabulary is the media. 
Learning media is one of learning sources which can consciously and independently assist students in the learning process [9]. Learning media cannot be separated from the learning process because learning media plays an important role in delivering messages and information from learning resources to the student. Without media, knowledge or material cannot be transferred to students maximally, or in more dangerous circumstance, it might be misinterpreted when students absorb it. Media in commonly teaching vocabulary is using picture in books, or flash card. Using picture in books will not have students to fully understand and comprehend what they are learning. Vocabulary learning needs a more sophisticated media because vocabulary is way too important to be neglected. It is impossible to learn English without learning vocabulary; even communication between people is words-based.

This era is marked with increasingly sophisticated technology. Educators convinced of the advantages in which new technologies have brought, actively exploring technologies and methodologies, though often hindered by factors such as technological acclimatization [10]-[12]. It is inevitably a digital era now. Daily life of current human era cannot be separated from technology as old and young people are using technology [13]-[15]. This has an impact also on human lifestyle [16]. New technologies such as PC (Personal Computer), PS (PlayStation) and other devices have refreshed the way how games are played. Nowadays, PC games are being utilized for something beyond an amusement. Some even contend that it is the ideal opportunity for games to manage increasingly genuine issues, for example, teaching. Lately, computer and online games have been thought as a potential learning media by plenty of educational researchers [17]-[21] and even game developers. Some arguments by these researchers regarding the potential use of computer games are that computer games can increase engagements in learners and increase active learning of students. Additionally, a game is defined as not the same as a simulation in that a game involves competition [22]. Some studies show the upsides of games in learning, not just for cross-over aptitudes like correspondence, coordinated effort, fine engine expertise, to give some examples yet additionally for explicit abilities specifically information areas [23].

Game that is going to be talked in this paper is educational game which contains of pure educational matter with minimal narration. Nobody denies that it is inevitable that kids tend to play video games or games that are digital and virtual through consoles. Even though so, teachers might use games in these consoles to be applied as an educational game to learn English. Unfortunately, these video games matter are sometimes be abused by children, whether they know it or not. It is a fact that plenty of times, game are being correlated with negativity of technology. It is very easy for children to get addicted to video games. An addiction to video games may vary in its type, e.g., completion related, mission, or achievement. Here is where language learning takes part. Language learning using games can be more interesting rather than being conducted in class [24]. Students could be addicted to sort games that support language learning, and in that circumstance, game has the positivity to make students addicted to them.

Moreover, with the assistance of PCs learning environments have become progressively intuitive and less exhausting especially in foreign language learning [25]. Vari- 
ous games contain plenty of animated characters and scene, also videos that have audio-visual objects in it. Audio-visual objects increase interactivity of students [26]. PC based games are getting progressively sensible and intelligent, which has expanded conversation about their potential for language learning [27]-[29]. Besides, PC game can help connect the separation among understudies and the objective language culture and in this way give sensible sociocultural settings to language learning [30].

The use of these games that are going to be used for learning is to increase students' engagement. This is what is called as gamification. Gamification is the use of gaming mechanics in order for people to be engaged with a product. Gamification interestingly, includes planning learning exercises so game qualities and game standards inhere inside the learning exercises themselves. To put it plainly, gamification applies game components or a game structure to existing learning exercises; gamebased learning plans learning exercises that are naturally match-up like. Gamification and game-based learning both advance commitment and continued inspiration in learning. Gamification in education is using and utilizing game concept into education sector [31]-[34]. Although the concept of gamification first was only intended to great ideas for business strategies, it is currently increasing the interest from other sectors, even education [35]. Gamification can be used to increase elements in education, such as engagement, and motivation. Be that as it may, educators as individual development adopters are accepted to assume a vital job in this advancement change measure for the selection of versatile innovations. Educators' experience factors, for example, age and sex, have been talked about in research writing regarding whether and how much they impact the utilization of ICT in class [36].

The existing studies have discovered a lot of proof of adequacy about vocabulary learning in online and PC games and reproductions [37]-[39]. These examinations have utilized an assortment of estimation conventions, for example, vocabulary acknowledgment, multiple choice, matching, or cloze tests. However, there are few studies on online game for EFL students. The ideal condition to be achieved is the need to develop a learning media in a form of online game such as SpellingCity . SpellingCity is an online game that allows students to access vocabularies test and learning. A research by Miller and Hegelheimer [40] explored whether organized play of the first form of SpellingCity, joined with extraordinarily planned learning materials, could permit L2 EFL students to utilize the game yet in addition to improve their English skills and engagement. In SpellingCity, teachers can input their vocabulary list to be taught and tested to their students.

One of the major problems of vocabulary learning that came up in a research of learning vocabulary is the limitation of source or media in learning vocabulary [41]. This research is expected to contribute on variety of media that can be used by English learners, especially in vocabulary through game. It is suggested that teachers should seek for methods that engage their students in a creative language use. By using vocabulary games, students can use the language more communicatively. The objective of this study is to explore the outcome of utilizing an online game "SpellingCity" to enrich vocabulary. To attain the purpose, two research problems are formulated: (1) how does SpellingCity lead to better vocabulary acquisition? and (2) how would SpellingCity be interesting to EFL students? 


\section{Literature Review}

Concerning instructing and learning measure, games are seen as sensible models working across formal and easygoing learning settings [42]. In language instructing, games have routinely been utilized to extend motivation and legitimate educational practices, since games have been conceptualized as a wonderful factor in language learning [43]. They make a lovely area where understudies and even the instructor become quicker on realizing what more, encouraging measure is. Additionally, games have been found as a certified and unpreventable segment for giving prompting and reenactment in enlightening settings. In easygoing settings, games have regularly been associated with the unwinding activities of children since gaming is a key development in children's off school practices and for the most part natural games outfit understudies with enlightening activities as they wreck around. Consequently, the game players will use the language and suitably learn it to participate in games [44]. Knowledge in gaming infers as correspondence structures in conversation, insight, transmission and enlistment. These understandings generally are feasible with open and socio-mental approaches to manage language and language learning, for instance the prioritization of game plan and enlightening limit [45]. In off school settings, kids commonly understand and use lingos as an open instrument, gathering information and gaming, however in schools the cognizance and usage of tongues is regularly seen to be the explanation behind doing the endeavors [46]. The effects of online EFL relationship on assurance, motivation, moreover, limit proposing bliss as a key factor in growing these learning factors [47]. This is moreover normal, since understudies who are exhausted or who don't see the impetus in a course won't have any kind of effect the exercise themselves. Since understudy centered unique learning grows fulfillment, EFL teachers need to recall such instruments for their activity plan. Instructors should endeavor to give their understudies profitable coordinated efforts with neighborhood speakers or professional speakers of English from a grouping of social orders, on interesting subjects. It is profitable, and along these lines fun, correspondences addition understudies' motivation provoking improved limit and sureness. The certified preferred position of such instrument isn't simply making understudies more anxious to partake in such activities, yet rather growing their trust in such an English affiliation, and besides advancing their English limit. Any sort of correspondence in the target language or with the target culture will finally improve the understudies' assurance, motivation, and limit.

The best models or practices of organizing and utilizing instructional gaming would be come about through mindfully controlling and fusing the three gatherings of essential variables, for instance, learning, understudy, and instructional course of action [48]. An examination explored the sufficiency of using games in training language to young understudies [49]. Teachers consider games to be an essential and significant bit of English language training and learning concerning grade schools' English exercises since they outfit EFL educators with various informative favorable circumstances. Games are reasonable in organizing young understudies' essentialness into language learning since energetic understudies like to be really unique; moreover, they are innovative and creative and adjust subconsciously. Thusly, demonstrating 
young understudies who need a particular endeavor and challenge by the teacher and games are probably the best ways to deal with achieve this. Regardless, to achieve games' inspiration, educators should consider certain components like picking which game to utilize and a chance to use the game in their classes [49]. An exploration named "Online jargon games as a device for teaching and learning English jargon" sound that understudies playing on the web jargon games will all in all become familiar with even more fittingly and could hold the new words for a more drawn-out time span and recuperate more words appeared differently in relation to the people who aren't outfitted with vocabulary games. Jargon direction is an enduring cycle. If the games are fun, loosening up, motivating and assurance boosting, the understudies' favorable position will augment. To end up being sure that learning continues, it is expected to check whether the games outfit the understudies with incessant motivation. In spite of the way that vitality is amazing in prodding understudies to play a game again, it is basic to end up being sure that the intensity segment does not conflictingly affect the get the learning goals. In unequivocal, such a vitality prompted by game playing is fundamentally associated with game capacities. Regardless, a need for refined game aptitudes to play enlightening games can be inconsequential abundance. Teachers ought to be cautious while conveying the games into the class. Information about organizing an effective exercise plan and aptitudes required for joining on the web parts into educating and learning measure are regarded imperative to become reasonable facilitator [50].

The key discoveries of the research are as follow:

1. Students and instructors the same, see internet games as successful vocabulary learning apparatuses.

2. Students lean toward internet games as an instructive guide when contrasted and conventional learning exercises.

3. To expand understudies' advantage and assurance learning adequacy, additionally inspiring games which give students with a feeling of accomplishment and extension for advancement are required.

4. Teachers imagine that their job as scientist and facilitator has developed more noticeable subsequent to utilizing data correspondence innovation (ICT) devices.

\section{$3 \quad$ Method}

\subsection{Participants}

The participants of this research were Freshmen of Islamic University at Malang, Indonesia. They were EFL Learners that still has sense of high school on them. There were 22 participants who consist of 11 male and 11 female. All of the participants in our study were aged 17-20. The participants were chosen because they understand the way how computer game works. 


\subsection{Research design}

The design of this research was that researchers require students to play SpellingCity online. In classroom, students were required to finish easy level of the quiz. First level of the quiz will have the database that is going to be the final result of students after doing the test. After that, students will take survey that is designed to measure students experience in playing SpellingCity .

Members gave their assent for utilizing the information gathered from class for research, academic distribution or potentially conference introduction. In the wake of having attempted the game, students were asked to finish an online survey about their suppositions on and perspectives towards utilizing internet games in learning vocabulary and its adequacy (see questions underneath). The survey was posted on Google Form. The study finishing rate among understudies was $100 \%$.

\subsection{Research instruments}

The researchers used two research instruments, namely survey (questionnaire) and interview. The survey was applied online. The instrument was a Likert-scaled survey intended to decide the gatherings of participants' view and experience of learning by means of SpellingCity .

There were eight statements on the survey which was fully answered by 22 participants. The survey's questions are listed below:

- Q1. I enjoyed playing SpellingCity .

- Q2. SpellingCity is easy to play.

- Q3. I learned new words by playing SpellingCity .

- Q4. Playing SpellingCity did NOT help me improve my English.

- Q5. Online games like SpellingCity can be useful for improving language ability.

- Q6. I would enjoy playing SpellingCity again in the future if I had the chance.

- Q7. I can evaluate my vocabulary learning progress by using SpellingCity .

- Q8. Online games are as useful for language learning as taking an English course.

Participants were required to fill in a range of 1-4 in which one indicates strongly disagree and four indicates strongly agree.

Interview was also done online in order to dig more information from the participants' sight of view. In order to do this, researchers made several questions that is answered by three random participants who have followed the survey before. The questions are:

- Q1. What do you think about the enjoyment of playing SpellingCity ?

- Q2. What do you think about the effect of playing SpellingCity towards your vocabulary? 


\subsection{Data analysis}

The researchers examined the information from the survey that filled by the members. The participants filled the survey dependent on their perspectives about the learning vocabulary utilizing games. So as to respond to the research questions, the information from the surveys was broke down by utilizing descriptive statistics. Descriptive statistics are utilized to sum up sets of mathematical information. For the principal stage, the researchers processed whole data from the survey and discovered the frequencies/percentage. In this research, the frequencies used to see the most elevated picked survey items.

\section{$4 \quad$ Results and Discussion}

The Research Question 1 corresponds to the Q3, Q4, Q5, and Q8. Participants has answered Q3 with the result of 50\% of the respondents (10 respondents) agree to the statement of "I learned new words by playing SpellingCity". Meanwhile, the rest of $50 \%$ of participants answers strongly agree to the statement. In Q4, a statement of "Playing SpellingCity did NOT help me improve my English" is provided and 65\% of respondents strongly disagree to the statements, and the rest 35\% disagree to the statements. Q5, "Online games like SpellingCity can be useful for improving language ability", $30 \%$ of the respondents agree to the statement and the rest $70 \%$ strongly agree to the statements. Lastly, Q8 has the statement of Online games are more useful for language learning than taking an English course. 80\% of the respondents agree to the statement, and the rest $20 \%$ strongly agree to the statement.

Table 1. The results of participants' responses on vocabulary acquisition of SpellingCity

\begin{tabular}{|l|l|c|c|c|c|}
\hline Q\# & \multicolumn{1}{|c|}{ Statements } & $\begin{array}{c}\text { Strongly } \\
\text { Disagree }\end{array}$ & Disagree & Agree & $\begin{array}{c}\text { Strongly } \\
\text { Disagree }\end{array}$ \\
\hline Q3 & I learned new words by playing SpellingCity & $0 \%$ & $0 \%$ & $50 \%$ & $50 \%$ \\
\hline Q4 & $\begin{array}{l}\text { llaying SpellingCity did NOT help me improve my } \\
\text { English. }\end{array}$ & $35 \%$ & $65 \%$ & $0 \%$ & $0 \%$ \\
\hline Q5 & $\begin{array}{l}\text { Online games like SpellingCity can be useful for } \\
\text { improving language ability. }\end{array}$ & $0 \%$ & $0 \%$ & $30 \%$ & $70 \%$ \\
\hline Q8 & $\begin{array}{l}\text { Online games are as helpful for language learning as } \\
\text { taking an English course. }\end{array}$ & $0 \%$ & $0 \%$ & $80 \%$ & $20 \%$ \\
\hline
\end{tabular}

Also, Q2 on the interview corresponds to this research question. Three respondents are asked this question of "What do you think about the effect of playing SpellingCity towards your vocabulary?" and each of their answers are presented in the following transcripts.

Respondent 1

"I feel that SpellingCity is very useful to increase our vocabulary. By doing one turn of the game, I learn up to five new vocabularies. Though, it needs more structured plan on making this online game as a successful media" 
Respondent 2

"SpellingCity has this awesome part that it shows the definitions and correct spelling of the vocabulary which helps us to increase our acquisition of the vocabulary."

\section{Respondent 3}

"I have played some games like this and this is one of the best one. Even though, the interface looks like an old-school game."

In according to the Research Question 1, both survey results and interview suggest that SpellingCity indeed has contribution to students' vocabulary acquisition. In survey results, $100 \%$ of the students whether agree or strongly agree to all positive statements in the survey (Q3, Q5, Q8) and $100 \%$ of the students whether disagree and strongly disagree to all negative statements (Q4). This suggests that every students feel that SpellingCity improve their vocabulary acquisition.

SpellingCity is an online game that provides not only vocabulary, but also spelling. Besides of showing the word and definition, it also shows how the vocabulary spelled and pronounced. This helps students to pronounce the word correctly to lead them to a better vocabulary acquisition. SpellingCity does not only provide students with only one game type. There are also more challenging games, e.g., Crosswords, Aim Your Word, etc.

The Research Question 2 corresponds to the Q1, Q2, Q6, and Q7. Participants has answered Q1 with the result of 10\% of the respondents agree to the statement of "I enjoyed playing SpellingCity ". Meanwhile, the rest of $90 \%$ of participants answers strongly agree to the statement. In Q2, a statement of "SpellingCity is easy to play" is provided and $75 \%$ of respondents agree to the statements, and the rest $25 \%$ strongly agree to the statements. Q6, "I would enjoy playing SpellingCity again in the future if I had the chance", $45 \%$ of the respondents agree to the statement and the rest $55 \%$ strongly agree to the statements. Lastly, Q7 has the statement of Online games are as helpful for language learning as taking an English course. 55\% of the respondents agree to the statement, and the rest $45 \%$ strongly agree to the statement.

Table 2. The results of participants' responses on the interesting of SpellingCity

\begin{tabular}{|c|l|c|c|c|c|}
\hline Q\# & \multicolumn{1}{|c|}{ Statements } & $\begin{array}{c}\text { Strongly } \\
\text { Disagree }\end{array}$ & Disagree & Agree & $\begin{array}{c}\text { Strongly } \\
\text { Agree }\end{array}$ \\
\hline Q1 & I enjoyed playing SpellingCity. & $0 \%$ & $0 \%$ & $10 \%$ & $90 \%$ \\
\hline Q2 & SpellingCity is easy to play & $0 \%$ & $0 \%$ & $75 \%$ & $25 \%$ \\
\hline Q6 & $\begin{array}{l}\text { I would enjoy playing SpellingCity again } \\
\text { in the future if I had the chance }\end{array}$ & $0 \%$ & $0 \%$ & $45 \%$ & $55 \%$ \\
\hline Q7 & $\begin{array}{l}\text { I would use SpellingCity as a language } \\
\text { learning tool if I had the chance }\end{array}$ & $0 \%$ & $0 \%$ & $55 \%$ & $45 \%$ \\
\hline
\end{tabular}

Also, Q1 on the interview corresponds to this research question. Three respondents are asked this question of "What do you think about the enjoyment of playing SpellingCity ?" and each of their answers are presented in the following transcripts. 


\section{Respondent 1}

"My first time playing this game was super easy. The design of the game is not complicated at all. Therefore, I enjoy the game because first impression was awesome."

\section{Respondent 2}

"I enjoy the game because the interface is simple. Though, it is too simple that it might look a bit old"

\section{Respondent 3}

"The game is easy to play and the design of the online game is also simple. Loving it since it is not as complicated as other online vocabulary game"

In accordance to the Research Question 2, both survey results and interview suggest that SpellingCity indeed is interesting towards participant. In survey results, $100 \%$ of the students whether agree or strongly agree to all positive statements in the survey (Q1, Q2, Q6, Q7). There are also no negative comments and feedback on the interview of the research. This result suggests that SpellingCity is an interesting platform to learn vocabulary.

The in-game interface of SpellingCity is super simple and engaging as shown in Fig. 1. Awesome transition, clear voice-over is made to make this online game perfect. Once students are in the game, they will only be told the word (in voice), sentence (in voice), and definition (in words) in order to guess the vocabulary. Students will be faced with up to ten vocabularies that needed to be guessed and learned throughout the quiz. Students can repeat each vocabularies pronunciation and sentence in case they forget the word that is being tested in the quiz.

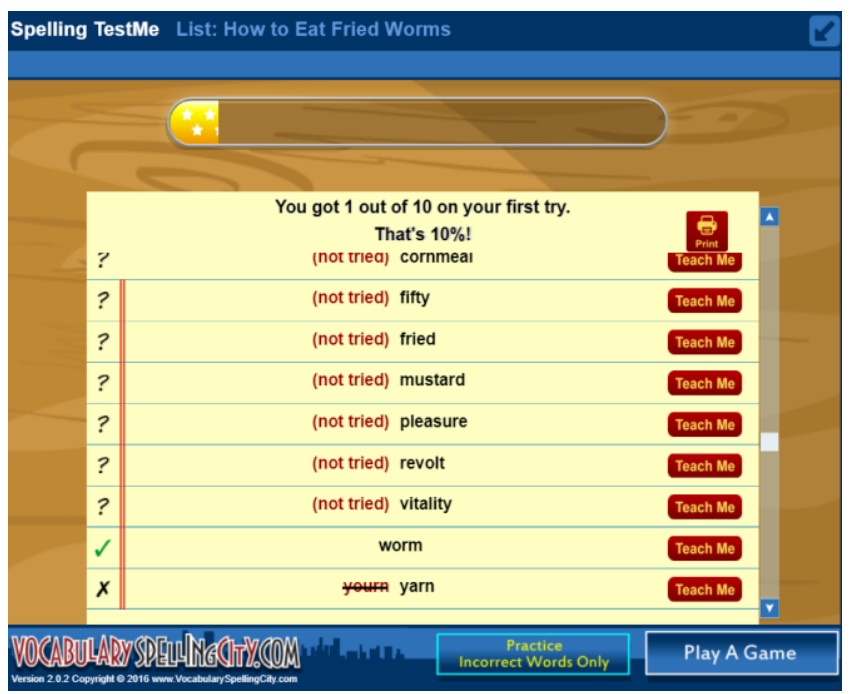

Fig. 1. The in-game interface of SpellingCity 
After all sessions are done, students are landed to a page where the result is listed on a table. Also, students are able to practice incorrect words only to make sure they understand words that they missed in the first attempt. The scoring is automatically done by the system. Teacher can have a glance of students' final result that is being provided by the game itself. The game also supports importing and exporting questions to ease teachers to upload quizzes for students to take by just using ttxt notepad format without having to waste too much time editing quizzes in website (online).

Several things to highlight in RQ 1 interview are that the results also defined that students can learn vocabularies through only one shot of SpellingCity. Analyzed further, teachers can use drilling to make this result even better. Drilling is a method that has been utilized in foreign language study classroom, which stresses on rehashing auxiliary example through on-and-on practice to show understudies' capacity in utilizing explicit language things in a controlled way [51]. Drilling is a technique for showing language through exchanges which accentuate on the understudies' propensity development by redundancy, remembering syntactic structures, and tense change, utilizing the target language and the way of life where the language is spoken [52]. Drilling can be used to make students gain more vocabularies. Drilling may enhance the use of SpellingCity itself. A structured and planned learning atmosphere may affect students' acquisition on vocabulary using SpellingCity .

Moreover, pronunciation is a part of learning a new vocabulary. Teaching and learning new vocabulary has customarily centered principally on the definitions and grammatical forms, yet pronunciation is plainly a significant factor in learning new words [53]. Hence, educators ought to encourage this learning by not just clarifying definitions yet additionally exhibiting the way to express these words. Word stress, vowels and consonant sounds, and word endings are pronunciation includes that are pertinent to educating and learning new vocabulary. An important aspect in learning vocabulary is more focused on correct pronunciation [53]. Without learning right way to pronounce words, people can do it without much of a stretch be misconstrued when talking or can misjudge the messages others are attempting to pass on to them. Pronunciation guidance offers understudies the chance to comprehend designs related with communicated in English, for example, designs demonstrating word pressure. By incorporating pronunciation and vocabulary in the study hall, we help understudies build up a superior mindfulness about these examples and the capacity to apply this information as they are presented to new words and pronunciations. When learning new words, there are a few elocution includes that ought to be fused in the learning process: word pressure, vowel and consonant sounds, and word endings. When learning word mixes, including phrasal action words, collocations, and sayings, understanding pronunciation highlights, for example, thought gatherings, musicality, connecting, and inflection is fundamental. This part further clarifies the significance of the fuse of pronunciation guidance in vocabulary learning and gives instances of how to do this and assets that can be utilized in the educating and learning of vocabulary what is more, pronunciation.

Encouraging pronunciation in relationship with instructing vocabulary is fundamental for second language securing as far as improving students' talking and tuning in abilities and informative skill [54]. As understudies learn new words, they ought to 
gain proficiency with the way to express each word notwithstanding learning the definition and spelling for each word. To encourage this, elocution highlights ought to be educated to set up an establishment in seeing how a word or pronunciation is articulated. These highlights incorporate rules for deciding right way to express word stress, vowel and consonant sounds, thought gatherings, musicality, and connecting. The different exercises and assets in this section are introduced to give a few different ways that elocution can be joined with vocabulary abilities. A large number of these exercises can be utilized at different degrees with youngsters or grown-ups just as with various levels. Joining elocution exercises, for example, those talked about in this section with vocabulary guidance gives a lot more extravagant learning experience for understudies and improves their oral utilization of words and pronunciations. To summarize, despite the fact that vocabulary may frequently be educated in relationship with perusing, it is significant that the oral utilization of the words be joined in the learning experience to improve oral/aural correspondence. In this way, learning rules for right elocution furnishes second language students with the instruments to state words all the more precisely and fluidly.

There are also other games similar to SpellingCity. Therefore, why SpellingCity could be one of best? It is because SpellingCity contains of more than just vocabulary quiz game. There is pronunciation, other interesting games to enhance vocabularies, even there are also shooting games that is meant to test students' vocabulary learning. Other interesting games makes students feel more interested to explore the game. Having them to explore the game more makes it easier for teachers to teach them vocabulary.

Secondly, things to highlight in RQ 2 interviews are first impression of game interface. A first impression to something is one of the most thing to make user wants to use it over again. The first impression of SpellingCity is not a bad one because user will directly be brought to the quiz and fun activity without having to face complicated things such as registering, or login, or moreover, payments. Many of other online games require users to register using their email, or make a new account, and even worse, ask for a premium account by paying a particular amount of money.

Also, simple interface eases students to access more games in the website. Games like crosswords aim your vocab, etc., can enhance students' vocabulary and engagement to the game. The more engagement of the students towards the game, the bigger chance of teacher can lead students to a better vocabulary acquisition. Student engagement is a pair of both students' individual and the situation [55]. As also known, Student engagement is a measure that mirrors the amount and nature of a student's support in their courses and each other part of their instructive program. Likewise, it echoes a student's collaboration and participation with co-students and teachers. As such, student commitment is the proportion of a conceivably effective learning experience for everybody concerned. It varies in intensity and duration.

Educating and learning new vocabulary has generally centered principally on the definitions and grammatical features, however pronunciation is unmistakably a significant factor in learning new words. Students' engagement is one of the most important aspects in learning process. To set it forth plainly, if students all total their tasks on schedule, produce brilliant outcomes, and take an interest in cooperative spaces like 
conversations, teachers can unhesitatingly say that they are locked in. Then again, in the event that they just complete tasks, however disregard different exercises like online classes and gathering questions, and their outcomes are poor, at that point they most likely need more engagement.

\section{Conclusion}

This examination has given additional proof that industrially created PC games able to, with hypothetical direction, be adjusted for use by EFL Students and also, further that advantageous EFL materials utilized to help such game can add to vocabulary procurement. The discoveries additionally recommend that PC games like SpellingCity are conceivably mainstream with EFL understudies from a wide assortment of foundations, and certain understudies might be available to the possibility of having such games fused into a language learning program under specific circumstances.

SpellingCity has positive results towards the participants that are it helps students to acquire vocabulary in interesting and new ways. Students claim that it helps them to acquire vocabularies in one shot of the game. It suggests that more shots of the game will help them more to acquire vocabularies, especially through clear direction and instruction. Also, the design and interface of the game surely took the interest of students as most of them claims that the interface is simple and interesting. As other games are complicated on its interface, SpellingCity gives a simple interface to ease students.

Referring back to two research questions this paper aims to answer, it is found that SpellingCity can improve students' vocabulary, in its note needed to have structured learning strategy in order to acquire better completion. By having students playing games, it will directly and indirectly lead them to a learning process. The second research question is aiming to see how SpellingCity would be interesting for students. The research found out that SpellingCity is interesting in its ease of play. However, the design is quite old in its interface. Even though it is so, the interface is easy to be understood.

However, this research limits itself to only tertiary level students in which makes big questions of how this online game would be used in other levels. Suggestions that is needed to be done for a further research is the other feature of SpellingCity should be explored more to see further impacts on student's English skill acquisition. Therefore, SpellingCity can be much more implemented as a learning platform for English skills.

\section{Acknowledgement}

The researchers much appreciate all students who have dedicated their time and energy to participate in this study. A special appreciation also goes to Universitas Islam Negeri Maulana Malik Ibrahim Malang, where the research was conducted, and 
the English Education Department was more than welcome to support the distribution of the questionnaire using their account.

\section{$7 \quad$ References}

[1] K. Csizér and E. H. Kontra, "Foreign Language Learning Characteristics of Deaf and Severely Hard-of-Hearing Students," Mod. Lang. J., vol. 104, no. 1, pp. 233-249, 2020. https://doi.org/10.1111/modl.12630

[2] N. Suryati and A. E. Fadilah, "English vocabulary knowledge of EFL engineering students," World Trans. Eng. Technol. Educ., vol. 17, no. 1, pp. 66-70, 2019.

[3] B. R. Aravind and V. Rajasekaran, "Technological modality to influence persuasive and argumentative vocabulary for effective communication with reference to selected TED talk videos,” Int. J. Recent Technol. Eng., vol. 7, no. 5, pp. 165-170, 2019.

[4] E. Peters, "The effect of imagery and on-screen text on foreign language vocabulary learning from audiovisual input," TESOL Q., vol. 53, no. 4, pp. 1008-1032, 2019. https://doi.org/10.1002/tesq.531

[5] E. Yaghi and A. Abdullah, "Understanding Online Reading Dispositions from the Perspective of Saudi EFL Learners," Int. J. Interact. Mob. Technol., vol. 14, no. 7, pp. 73-87, 2020. https://doi.org/10.3991/ijim.v14i07.11062

[6] H. Bell and S. Ainsworth, "Difficulties assessing knowledge of grammatical terminology: Implications for teacher education and teaching," Lang. Aware., pp. 1-17, 2020, doi: https://doi.org/10.1080/09658416.2020.1752701

[7] D. Atay, "Beginning teacher efficacy and the practicum in an EFL context," Teach. Dev., vol. 11, no. 2, pp. 203-219, 2007. https://doi.org/10.1080/13664530701414720

[8] I. Kazaz, "Alternative Vocabulary Assessment: Using Concordance Line Activities for Testing Lexical Knowledge.," Int. Online J. Educ. Teach., vol. 7, no. 3, pp. 1221-1238, 2020.

[9] A. I. Suryani, Anwar, Hajidin, and I. Rofiki, "The practicality of mathematics learning module on triangles using GeoGebra," J. Phys. Conf. Ser., vol. 1470, no. 1, p. 012079, 2020, https://doi.org/10.1088/1742-6596/1470/1/012079

[10] M. Kalogiannakis and S. Papadakis, "The Use of Developmentally Mobile Applications for Preparing Pre-Service Teachers to Promote STEM Activities in Preschool Classrooms," in Mobile Learning Applications in Early Childhood Education, IGI Global, 2020, pp. 82-100. https://doi.org/10.4018/978-1-7998-1486-3.ch005

[11] S. Papadakis, M. Kalogiannakis, E. Sifaki, and N. Vidakis, "Access moodle using smart mobile phones. A case study in a Greek University," in Interactivity, Game Creation, Design, Learning, and Innovation, Springer, 2017, pp. 376-385. https://doi.org/10.1007/ 978-3-319-76908-0_36

[12] N. Vidakis, A. K. Barianos, A. M. Trampas, S. Papadakis, M. Kalogiannakis, and K. Vassilakis, "Generating Education in-Game Data: The Case of an Ancient Theatre Serious Game.," in CSEDU (1), 2019, pp. 36-43. https://doi.org/10.5220/000781080 0360043

[13] H. Douglas, B. A. Harris, and M. Dragiewicz, "Technology-facilitated domestic and family violence: Women's experiences,” Br. J. Criminol., vol. 59, no. 3, pp. 551-570, 2019. https://doi.org/10.1093/bjc/azy068

[14] J. Nie, P. Wang, and L. Lei, "Why can't we be separated from our smartphones? The vital roles of smartphone activity in smartphone separation anxiety," Comput. Human Behav., vol. 109, p. 106351, 2020, https://doi.org/10.1016/j.chb.2020.106351

[15] L. Plowman, "Rethinking context: Digital technologies and children's everyday lives," Child. Geogr., vol. 14, no. 2, pp. 190-202, 2016. https://doi.org/10.1080/14733285. $\underline{2015.1127326}$ 
[16] R. Amelia, I. Rofiki, H. S. Tortop, and J. A. Abah, "Pre-service teachers' scientific explanation with e-scaffolding in blended learning," J. Ilm. Pendidik. Fis. Al-Biruni, vol. 9, no. 1, pp. 33-40, 2020. https://doi.org/10.24042/jipfalbiruni.v9i1.5091

[17] M. Dezuanni, "Minecraft and children's digital making: Implications for media literacy education," Learn. Media Technol., vol. 43, no. 3, pp. 236-249, 2018. https://doi.org/10.1080/17439884.2018.1472607

[18] A. Skulmowski and G. D. Rey, "Subjective cognitive load surveys lead to divergent results for interactive learning media," Hum. Behav. Emerg. Technol., vol. 2, no. 2, pp. 149-157, 2020. https://doi.org/10.1002/hbe2.184

[19] E. Gee, S. Siyahhan, and A. M. Cirell, "Video gaming as digital media, play, and family routine: implications for understanding video gaming and learning in family contexts," Learn. Media Technol., vol. 42, no. 4, pp. 468-482, 2017. https://doi.org/10. $\underline{1080 / 17439884.2016 .1205600}$

[20] H. Melander Bowden, "Problem-solving in collaborative game design practices: epistemic stance, affect, and engagement," Learn. Media Technol., vol. 44, no. 2, pp. 124-143, 2019. https://doi.org/10.1080/17439884.2018.1563106

[21] J. Chen et al., "Blended learning in basic medical laboratory courses improves medical students' abilities in self-learning, understanding, and problem solving," Adv. Physiol. Educ., vol. 44, no. 1, pp. 9-14, 2020. https://doi.org/10.1152/advan.00076.2019

[22] F. Ke, "A qualitative meta-analysis of computer games as learning tools," in Gaming and simulations: Concepts, methodologies, tools and applications, IGI Global, 2011, pp. 16191665. https://doi.org/10.4018/978-1-60960-195-9.ch701

[23] S. Papadakis, "Evaluating a game-development approach to teach introductory programming concepts in secondary education," Int. J. Technol. Enhanc. Learn., vol. 12, no. 2, pp. 127-145, 2020. https://doi.org/10.1504/ijtel.2020.106282

[24] E. Gozcu and C. K. Caganaga, "The Importance of Using Games in EFL Classrooms.," Cypriot J. Educ. Sci., vol. 11, no. 3, pp. 126-135, 2016. https://doi.org/10.18844/ cjes.v11i3.625

[25] M. Demirbilek, E. Y1lmaz, and S. Tamer, "Second language instructors' perspectives about the use of educational games," Procedia-Social Behav. Sci., vol. 9, pp. 717-721, 2010. https://doi.org/10.1016/j.sbspro.2010.12.223

[26] A. Smolic and P. Kauff, "Interactive 3-D video representation and coding technologies," Proc. IEEE, vol. 93, no. 1, pp. 98-110, 2005. https://doi.org/10.1109/jproc.2004. $\underline{839608}$

[27] R. Purushotma, "Commentary: You're not studying, you're just...," Lang. Learn. Technol., vol. 9, no. 1, pp. 80-96, 2005.

[28] Y.-J. Lan, I. Y. T. Hsiao, and M.-F. Shih, "Effective learning design of game-based 3D virtual language learning environments for special education students," J. Educ. Technol. Soc., vol. 21, no. 3, pp. 213-227, 2018.

[29] T. Singh and J. Mishra, "Learning with Artificial Intelligence Systems: Application, Challenges, and Opportunities," in Impact of AI Technologies on Teaching, Learning, and Research in Higher Education, IGI Global, 2020, pp. 236-253.

[30] K. Schwienhorst, "Why virtual, why environments? Implementing virtual reality concepts in computer-assisted language learning," Simul. Gaming, vol. 33, no. 2, pp. 196-209, 2002. https://doi.org/10.1177/1046878102033002008

[31] S. Papadakis and M. Kalogiannakis, "Using gamification for supporting an introductory programming course. The case of classcraft in a secondary education classroom," in Interactivity, game creation, design, learning, and innovation, Springer, 2017, pp. 366-375. https://doi.org/10.1007/978-3-319-76908-0 35

[32] M. Kalogiannakis and S. Papadakis, "Evaluating pre-service kindergarten teachers' intention to adopt and use tablets into teaching practice for natural sciences," Int. J. Mob. Learn. 
Organ., vol. 13, no. 1, pp. 113-127, 2019. https://doi.org/10.1504/ijmlo.2019.1001 $\underline{6617}$

[33] S. Papadakis and M. Kalogiannakis, "A Research Synthesis of the Real Value of SelfProclaimed Mobile Educational Applications for Young Children," in Mobile Learning Applications in Early Childhood Education, IGI Global, 2020, pp. 1-19. https://doi.org/10.4018/978-1-7998-1486-3.ch001

[34] K. M. Kapp, The gamification of learning and instruction: game-based methods and strategies for training and education. John Wiley \& Sons, 2012.

[35] C. Poondej and T. Lerdpornkulrat, "The development of gamified learning activities to increase student engagement in learning," Aust. Educ. Comput., vol. 31, no. 2, pp. 1-16, 2016.

[36] S. Papadakis, "Evaluating pre-service teachers' acceptance of mobile devices with regards to their age and gender: a case study in Greece," Int. J. Mob. Learn. Organ., vol. 12, no. 4, pp. 336-352, 2018. https://doi.org/10.1504/ijmlo.2018.10013372

[37] J. B. Redd and D. Schmidt, "Using mobile devices and gaming as a means of building vocabulary," Int. J. Interact. Mob. Technol., vol. 5, no. 4, pp. 30-38, 2011. https://doi.org/10.3991/ijim.v5i4.1683

[38] W. Alsharafat, W. K. Alrashdan, and M. B. Younes, "The effect of using an electronic instructional game in improving English language vocabulary for third graders in Irbid city," Int. J. Interact. Mob. Technol., vol. 11, no. 6, pp. 123-135, 2017. https://doi.org/10.3991/ijim.v11i6.7417

[39] C.-H. Lai, B.-S. Jong, Y.-T. Hsia, and T.-W. Lin, "Integrating Flash Cards with Narratives for Mobile Learning of English Vocabulary,” Int. J. Interact. Mob. Technol., vol. 14, no. 4, pp. 4-16, 2020. https://doi.org/10.3991/ijim.v14i04.11723

[40] M. Miller and V. Hegelheimer, "The SIMs meet ESL Incorporating authentic computer simulation games into the language classroom," Interact. Technol. smart Educ., vol. 3, no. 4, pp. 311-328, 2006. https://doi.org/10.1108/17415650680000070

[41] S. Elashhab, "Exploring vocabulary learning strategies of Saudi female university students: Perspectives and use," Int. J. Lang. Linguist., vol. 6, no. 3, pp. 47-55, 2019. https://doi.org/10.30845/ijll.v6n3p7

[42] J. Kang, J. Moon, and M. Diederich, "Educational Games and Gamification: From Foundations to Applications of Data Analytics," in Data Analytics Approaches in Educational Games and Gamification Systems, Springer, 2019, pp. 3-23. https://doi.org/10.1007/ 978-981-32-9335-9 1

[43] S. W. P. Knight, L. Marean, and J. M. Sykes, "Gaming and informal language learning," Handb. Informal Lang. Learn., pp. 101-115, 2019. https://doi.org/10.1002/978 1119472384.ch7

[44] Q.-F. Yang, S.-C. Chang, G.-J. Hwang, and D. Zou, "Balancing cognitive complexity and gaming level: Effects of a cognitive complexity-based competition game on EFL students' English vocabulary learning performance, anxiety and behaviors," Comput. Educ., vol. 148, p. 103808, 2020. https://doi.org/10.1016/j.compedu.2020.103808

[45] R. E. S. Santos, C. V. C. Magalhães, L. F. Capretz, J. S. Correia-Neto, F. Q. B. da Silva, and A. Saher, "Computer games are serious business and so is their quality: particularities of software testing in game development from the perspective of practitioners," in Proceedings of the 12th ACM/IEEE International Symposium on Empirical Software Engineering and Measurement, 2018, pp. 1-10. https://doi.org/10.1145/3239235. $\underline{3268923}$

[46] D. J. Shernoff, J.-C. Ryu, E. Ruzek, B. Coller, and V. Prantil, "The Transportability of a Game-Based Learning Approach to Undergraduate Mechanical Engineering Education: Effects on Student Conceptual Understanding, Engagement, and Experience," Sustainability, vol. 12, no. 17, p. 6986, 2020. https://doi.org/10.3390/su12176986 
[47] W. V. Wu, L. L. Yen, and M. Marek, "Using online EFL interaction to increase confidence, motivation, and ability," J. Educ. Technol. Soc., vol. 14, no. 3, pp. 118-129, 2011.

[48] R. Mathew, S. I. Malik, and R. M. Tawafak, "Teaching Problem Solving Skills using an Educational Game in a Computer Programming Course.," Informatics Educ., vol. 18, no. 2, pp. 359-373, 2019. https://doi.org/10.15388/infedu.2019.17

[49] G. Yolageldili and A. Arikan, "Effectiveness of using games in teaching grammar to young learners.," Online Submiss., vol. 10, no. 1, pp. 219-229, 2011.

[50] E. Sinha and K. Bagarukayo, "Online Education in Emerging Knowledge Economies: Exploring factors of motivation, de-motivation and potential facilitators; and studying the effects of demographic variables.," Int. J. Educ. Dev. Using Inf. Commun. Technol., vol. 15, no. 2, pp. 5-30, 2019.

[51] J. Harmer, "How to Teach English: An Introduction to the Practice of English Language Teaching New York: Pearson ELT," 2007.

[52] B. Setiyadi, "Teaching English as a foreign language," Yogyakarta Graha Ilmu, 2006.

[53] K. Ahmad, "Integrating pronunciation with vocabulary skills," Pronunciation Classr. overlooked Essent., pp. 1-15, 2016.

[54] S. H. Terrell, Elements of music and speech: A methodology to incorporate the elements of music into teaching pronunciation to speakers of English as a second language. The University of Texas at Dallas, 2012.

[55] J. Martin and A. Torres, "What is student engagement and why is it important," Natl. Assoc. Indep. Sch., 2016.

\section{Authors}

Dr. Like Raskova Octaberlina, M.Ed. was born in Malang, Indonesia. She is a senior lecturer of English education at Universitas Islam Negeri Maulana Malik Ibrahim Malang. She graduated with a bachelor's degree in English education from Universitas Negeri Malang, and a master's degree in English education form Monash University, Australia. She obtained a doctor's degree in English education from Universitas Negeri Malang. Her research interests are literature, online learning, TEFL, and EFL. Email: likeraskova2004@gmail.com

Dr. Imam Rofiki, M. Pd was born in Jombang, Indonesia. He is a lecturer and researcher of mathematics education at Universitas Islam Negeri Maulana Malik Ibrahim Malang. He gained bachelor program of mathematics, and master of mathematics education from Universitas Negeri Surabaya. He graduated his doctoral program in mathematics education from Universitas Negeri Malang. His research interests are thinking process, reasoning, ethnomathematics, learning trajectory, digital media, mobile learning, blended learning, e-content, and graph theory. E-mail: imam.rofiki@uin-malang.ac.id

Article submitted 2020-08-03. Resubmitted 2020-10-10. Final acceptance 2020-10-13. Final version published as submitted by the authors. 